\title{
INFLUENCE OF THE ISOTHERMAL ANNEALING \\ ON THE FREE VOLUME CHANGES \\ IN THERMO-SHRUNKEN POLYETHYLENE BY POSITRON ANNIHILATION
}

\author{
W. Osoba \\ Institute of Physics, Silesian University, Uniwersytecka 4, 40-007 Katowice, Poland
}

Positron lifetime measurements in polyethylene have been performed. Samples of the polyethylene were isothermally annealed at three temperatures $(373 \mathrm{~K}, 423 \mathrm{~K}$, and $473 \mathrm{~K}$ ) for different time periods (from $5 \mathrm{~min}$ to $5 \mathrm{~h}$ ). After cooling, the samples were used for the lifetime measurements in air at room temperature. A conventional fast-slow coincidence lifetime spectrometer with plastic scintillators has been used to perform the lifetime measurements. Mean free volumes radii and fractional free volume have been calculated from the lifetime data.

PACS numbers: $71.60 .+\mathrm{z}, 78.70 . \mathrm{Bj}$

\section{Introduction}

Positron annihilation spectroscopy is widely used for investigations of different aspects of polymer properties [1,2] and positron behaviour in polymers. The thermalised positron can annihilate with an electron from the absorber or it may form, with this electron, a bound system — positronium ( $\mathrm{Ps})$. In amorphous regions of a polymer substance free volumes exist, where ortho-positronium (o-Ps) may live for several ns. Many different external conditions can perturb the fate of the positron in polymer matter and due to this, they might change its lifetime. Polyethylene (PE) is one of the most common polymers. It is used all over the world for different purposes. It is also investigated by numerous authors [3-8]. The purpose of this paper was to investigate the influence of the isothermal annealing on the free volume changes in thermo-shrunken PE.

\section{Experimental}

\subsection{The spectrometer and the source characteristics}

A conventional slow-fast coincidence spectrometer with plastic scintillators has been used. The time resolution of the spectrometer, approximated by two 
Gaussian curves, has been determined by analysing the measurements of the positron lifetimes in Kapton foils. Typical values of the full widths at half of the maximum $\left(\mathrm{FWHM}_{i}\right)$ have been as follows: $\mathrm{FWHM}_{1}$ about $257 \mathrm{ps}$ and $I_{1}$ about $70 \% ; \mathrm{FWHM}_{2}$ about $360 \mathrm{ps}$. Positron lifetime spectra have been accumulated to approximately $(2.5) \times 10^{6}$ counts. A positron source (about $0.2 \mathrm{MBq}$ ) was sealed between two Kapton foils ( $8 \mu \mathrm{m}$ thick). The source correction has been taken into account during numerical evaluations. All of the measurements have been performed in air at room temperature. The measurements have been repeated at least twice for each sample. The values of the parameters obtained after numerical analyses of the raw lifetime spectra have been reproducible.

\subsection{The samples}

All of the measured samples were made of PE produced by the Institute of Nuclear Chemistry and Technology, Warsaw (Poland) as thermo-shrunken sheets used for electric cables insulation. This Institute used granules of Lupolen 2012D, schwarz 413 (made by BASF) for production of the sheets. The density of the granules was $0.933-0.939 \mathrm{~g} / \mathrm{cm}^{3}$. The samples $(9 \mathrm{~mm}$ in diameter) were cut down from a $1.3 \mathrm{~mm}$ thick sheet. The positron source was sandwiched between two pairs of such discs. Three different types of samples were used for investigations. The samples of first type were cut down from the sheet of the PE without any modification during the technological process (they are described in the paper: the as-produced samples). The samples of the second type were prepared from the sheet of the PE irradiated by electrons during the production process, they are described in the article: the irradiated samples. Finally, the third types were made of the "orientated" PE sheet (it means the sheet was lengthened in the course of production process at elevated temperature). These types of the samples are described in the article: the orientated samples. The samples were isothermally annealed, at three different temperatures $(373 \mathrm{~K}, 423 \mathrm{~K}$, and $473 \mathrm{~K}$ ) before the measurements, in an oven, in air. Annealing at higher temperatures caused melting of the samples. The time of the annealing was also changed (from $0 \mathrm{~min}$, the non-annealed sample to $300 \mathrm{~min}$ ). Additional measurements for thermal characterisation of the samples were performed by differential scanning calorimetry (DSC), a heating rate: $20 \mathrm{~K} / \mathrm{min}$. The melting $\left(T_{\mathrm{m}}\right)$ points were defined as the maximum of the melting endotherm (of the DSC trace). For all the investigated samples $T_{\mathrm{m}}=(381 \pm 5) \mathrm{K}$.

\section{Results}

The positron lifetime spectra were analysed using the package programs PATFIT-88 [9]. These programs have fitted four exponential components to the measured spectra. No constraints on lifetimes and intensities have been imposed during numerical calculations. The longest-lived component, $\tau_{4}$, is attributed to the pick-off annihilation of o-Ps. According to the model proposed by Tao [10] and Eldrup et al. [11], the longest-lived component of the positron lifetime spectrum may be correlated with the mean radius of the free volume cavity in the polymer matter. They derived the following equation:

$$
\tau_{4}=0.5\{1-R /(R+0.1656)+(1 / 2 \pi) \sin [2 \pi R /(R+0.1656)]\}^{-1},
$$


where $\tau_{4}$ is the $o$-Ps lifetime expressed in nanoseconds, $R$ is the mean radius of the spherical well expressed in $\mathrm{nm}$, and $0.1656 \mathrm{~nm}$ is an empirical constant.

The aim of this investigation was to find out a relation between the annealing parameters of the thermo-shrunken $\mathrm{PE}$ and the mean radius of the free volume cavity. This is the reason why only $\tau_{4}, I_{4}$, and $R$ values (calculated according to Eq. (1)) are listed, as the results of this investigation, in Tables I, II, and III, for three types of the samples, respectively.

TABLE I

$\tau_{4}, I_{4}$, and $R$ values obtained for the as-produced samples.

\begin{tabular}{|c|c|c|c|c|c|c|c|c|c|}
\hline \multirow{3}{*}{$\begin{array}{l}\text { Anne- } \\
\text { aling } \\
\text { time } \\
{[\mathrm{min}]}\end{array}$} & $\begin{array}{c}\tau_{4} \\
{[\mathrm{ps}]}\end{array}$ & $\begin{array}{c}I_{4} \\
{[\%]}\end{array}$ & $\begin{array}{c}R \\
{[\mathrm{~nm}]}\end{array}$ & $\begin{array}{c}\tau_{4} \\
{[\mathrm{ps}]}\end{array}$ & $\begin{array}{c}I_{4} \\
{[\%]}\end{array}$ & $\begin{array}{c}R \\
{[\mathrm{~nm}]}\end{array}$ & $\begin{array}{c}\tau_{4} \\
{[\mathrm{ps}]}\end{array}$ & $\begin{array}{c}I_{4} \\
{[\%]}\end{array}$ & $\begin{array}{c}R \\
{[\mathrm{~nm}]}\end{array}$ \\
\hline & \multicolumn{9}{|c|}{ Annealing temperature } \\
\hline & \multicolumn{3}{|c|}{$373 \mathrm{~K}$} & \multicolumn{3}{|c|}{$423 \mathrm{~K}$} & \multicolumn{3}{|c|}{$473 \mathrm{~K}$} \\
\hline \multirow[t]{2}{*}{0} & 2587 & 21.88 & 0.333 & 2587 & 21.88 & 0.333 & & 21.88 & 0.333 \\
\hline & \pm 20 & \pm 0.47 & \pm 0.002 & \pm 20 & \pm 0.47 & \pm 0.002 & \pm 20 & \pm 0.47 & \pm 0.002 \\
\hline \multirow[t]{2}{*}{5} & 2616 & 21.14 & 0.336 & 2620 & 21.72 & 0.336 & 2615 & 21.71 & 0.336 \\
\hline & \pm 22 & \pm 0.51 & \pm 0.002 & \pm 21 & \pm 0.51 & \pm 0.002 & \pm 20 & \pm 0.50 & \pm 0.002 \\
\hline \multirow[t]{2}{*}{10} & 2580 & 22.07 & 0.333 & 2643 & 21.45 & 0.338 & 2617 & 21.72 & 0.336 \\
\hline & \pm 23 & \pm 0.61 & \pm 0.002 & \pm 23 & \pm 0.57 & \pm 0.002 & \pm 18 & \pm 0.42 & \pm 0.001 \\
\hline \multirow[t]{2}{*}{15} & 2575 & 22.20 & 0.333 & 2618 & 22.01 & 0.336 & 2600 & 20.76 & 0.334 \\
\hline & \pm 22 & \pm 0.56 & \pm 0.002 & \pm 21 & \pm 0.53 & \pm 0.002 & \pm 29 & \pm 0.74 & \pm 0.002 \\
\hline \multirow[t]{2}{*}{30} & 2632 & 21.46 & 0.337 & 2616 & 21.84 & 0.336 & 2559 & 21.97 & 0.331 \\
\hline & \pm 19 & \pm 0.45 & \pm 0.001 & \pm 18 & \pm 0.41 & \pm 0.001 & \pm 17 & \pm 0.40 & \pm 0.001 \\
\hline \multirow[t]{2}{*}{60} & 2647 & 21.56 & 0.338 & 2575 & 21.78 & 0.333 & 2577 & 21.85 & 0.333 \\
\hline & \pm 20 & \pm 0.47 & \pm 0.001 & \pm 24 & \pm 0.65 & \pm 0.002 & \pm 24 & \pm 0.61 & \pm 0.002 \\
\hline \multirow[t]{2}{*}{120} & 2606 & 21.94 & 0.335 & 2569 & 22.23 & 0.332 & 2599 & 22.12 & 0.334 \\
\hline & \pm 18 & \pm 0.38 & \pm 0.001 & \pm 18 & \pm 0.43 & \pm 0.001 & \pm 19 & \pm 0.46 & \pm 0.001 \\
\hline \multirow[t]{2}{*}{180} & 2612 & 21.95 & 0.335 & 2624 & 20.97 & 0.336 & 2595 & 22.61 & 0.334 \\
\hline & \pm 20 & \pm 0.48 & \pm 0.002 & \pm 20 & \pm 0.47 & \pm 0.002 & \pm 19 & \pm 0.50 & \pm 0.002 \\
\hline \multirow[t]{2}{*}{240} & 2595 & 22.18 & 0.334 & 2593 & 20.75 & 0.334 & 2631 & 21.32 & 0.337 \\
\hline & \pm 17 & \pm 0.41 & \pm 0.001 & \pm 21 & \pm 0.48 & \pm 0.002 & \pm 29 & \pm 0.80 & \pm 0.002 \\
\hline \multirow[t]{2}{*}{300} & 2654 & 20.62 & 0.338 & 2590 & 21.41 & 0.334 & 2596 & 21.85 & 0.334 \\
\hline & \pm 29 & \pm 0.72 & \pm 0.002 & \pm 23 & \pm 0.58 & \pm 0.002 & \pm 21 & \pm 0.52 & \pm 0.002 \\
\hline
\end{tabular}


TABLE II

$\tau_{4}, I_{4}$, and $R$ values obtained for the irradiated samples.

\begin{tabular}{|c|c|c|c|c|c|c|c|c|c|}
\hline \multirow{3}{*}{$\begin{array}{l}\text { Anne- } \\
\text { aling } \\
\text { time } \\
\text { [min] }\end{array}$} & $\begin{array}{c}\tau_{4} \\
{[\mathrm{ps}]}\end{array}$ & $\begin{array}{c}I_{4} \\
{[\%]}\end{array}$ & $\begin{array}{c}R \\
{[\mathrm{~nm}]}\end{array}$ & $\begin{array}{c}\tau_{4} \\
{[\mathrm{ps}]}\end{array}$ & $\begin{array}{c}I_{4} \\
{[\%]}\end{array}$ & $\begin{array}{c}R \\
{[\mathrm{~nm}]}\end{array}$ & $\begin{array}{c}\tau_{4} \\
{[\mathrm{ps}]}\end{array}$ & $\begin{array}{c}I_{4} \\
{[\%]}\end{array}$ & $\begin{array}{c}R \\
{[\mathrm{~nm}]}\end{array}$ \\
\hline & \multicolumn{9}{|c|}{ Annealing temperature } \\
\hline & \multicolumn{3}{|c|}{$373 \mathrm{~K}$} & \multicolumn{3}{|c|}{$423 \mathrm{~K}$} & \multicolumn{3}{|c|}{$473 \mathrm{~K}$} \\
\hline \multirow[t]{2}{*}{0} & 2540 & 19.89 & 0.330 & 2540 & 19.89 & 0.330 & 2540 & 19.89 & 0.330 \\
\hline & \pm 20 & \pm 0.42 & \pm 0.002 & \pm 20 & \pm 0.42 & \pm 0.002 & \pm 20 & \pm 0.42 & \pm 0.002 \\
\hline \multirow[t]{2}{*}{5} & 2543 & 21.21 & 0.330 & 2564 & 21.79 & 0.332 & 2590 & 22.31 & 0.334 \\
\hline & \pm 20 & \pm 0.48 & \pm 0.002 & \pm 28 & \pm 0.77 & \pm 0.002 & \pm 22 & \pm 0.57 & \pm 0.002 \\
\hline \multirow[t]{2}{*}{10} & 2566 & 21.59 & 0.332 & 2551 & 22.79 & 0.331 & 2682 & 21.51 & 0.341 \\
\hline & \pm 20 & \pm 0.47 & \pm 0.002 & \pm 18 & \pm 0.43 & \pm 0.001 & \pm 24 & \pm 0.60 & \pm 0.002 \\
\hline \multirow[t]{2}{*}{15} & 2565 & 20.97 & 0.332 & 2579 & 21.84 & 0.333 & 2677 & 21.50 & 0.340 \\
\hline & \pm 17 & \pm 0.37 & \pm 0.001 & \pm 30 & \pm 0.89 & \pm 0.002 & \pm 25 & \pm 0.62 & \pm 0.002 \\
\hline \multirow[t]{2}{*}{30} & 2552 & 22.17 & 0.331 & 2588 & 21.98 & 0.334 & 2638 & 22.74 & 0.337 \\
\hline & \pm 18 & \pm 0.42 & \pm 0.001 & \pm 27 & \pm 0.77 & \pm 0.002 & \pm 24 & \pm 0.66 & \pm 0.002 \\
\hline \multirow[t]{2}{*}{60} & 2584 & 21.23 & 0.333 & 2574 & 22.37 & 0.333 & 2668 & 22.15 & 0.340 \\
\hline & \pm 19 & \pm 0.45 & \pm 0.001 & \pm 23 & \pm 0.61 & \pm 0.002 & \pm 22 & \pm 0.55 & \pm 0.002 \\
\hline \multirow[t]{2}{*}{120} & 2577 & 22.11 & 0.333 & 2612 & 21.83 & 0.335 & 2667 & 22.59 & 0.339 \\
\hline & \pm 19 & \pm 0.48 & \pm 0.001 & \pm 33 & \pm 0.98 & \pm 0.003 & \pm 20 & \pm 0.49 & \pm 0.002 \\
\hline \multirow[t]{2}{*}{180} & 2573 & 21.56 & 0.332 & 2572 & 22.11 & 0.332 & 2603 & 22.99 & 0.335 \\
\hline & \pm 22 & \pm 0.57 & \pm 0.002 & \pm 25 & \pm 0.69 & \pm 0.002 & \pm 60 & \pm 1.96 & \pm 0.004 \\
\hline \multirow[t]{2}{*}{240} & 2587 & 21.79 & 0.333 & 2605 & 22.14 & 0.335 & 2528 & 22.53 & 0.329 \\
\hline & \pm 19 & \pm 0.45 & \pm 0.001 & \pm 23 & \pm 0.59 & \pm 0.002 & \pm 18 & \pm 0.65 & \pm 0.001 \\
\hline \multirow[t]{2}{*}{300} & 2535 & 22.40 & 0.329 & 2573 & 22.39 & 0.332 & 2573 & 20.12 & 0.332 \\
\hline & \pm 16 & \pm 0.37 & \pm 0.001 & \pm 20 & \pm 0.49 & \pm 0.002 & \pm 18 & \pm 0.37 & \pm 0.001 \\
\hline
\end{tabular}


TABLE III

$\tau_{4}, I_{4}$, and $R$ values obtained for the orientated samples.

\begin{tabular}{|c|c|c|c|c|c|c|c|c|c|}
\hline \multirow{3}{*}{$\begin{array}{l}\text { Anne- } \\
\text { aling } \\
\text { time } \\
\text { [min] }\end{array}$} & $\begin{array}{c}\tau_{4} \\
{[\mathrm{ps}]}\end{array}$ & $\begin{array}{c}I_{4} \\
{[\%]}\end{array}$ & $\begin{array}{c}R \\
{[\mathrm{~nm}]}\end{array}$ & $\begin{array}{c}\tau_{4} \\
{[\mathrm{ps}]}\end{array}$ & $\begin{array}{c}I_{4} \\
{[\%]}\end{array}$ & $\begin{array}{c}R \\
{[\mathrm{~nm}]}\end{array}$ & $\begin{array}{c}\tau_{4} \\
{[\mathrm{ps}]}\end{array}$ & $\begin{array}{c}I_{4} \\
{[\%]}\end{array}$ & $\begin{array}{c}R \\
{[\mathrm{~nm}]}\end{array}$ \\
\hline & \multicolumn{9}{|c|}{ Annealing temperature } \\
\hline & \multicolumn{3}{|c|}{$373 \mathrm{~K}$} & \multicolumn{3}{|c|}{$423 \mathbf{K}$} & \multicolumn{3}{|c|}{$473 \mathrm{~K}$} \\
\hline \multirow[t]{2}{*}{0} & 2609 & 21.62 & 0.335 & 2609 & 21.62 & 0.335 & 2609 & 21.62 & 0.335 \\
\hline & \pm 20 & \pm 0.46 & \pm 0.001 & \pm 20 & \pm 0.46 & \pm 0.001 & \pm 20 & \pm 0.46 & \pm 0.001 \\
\hline \multirow[t]{2}{*}{5} & 2628 & 22.11 & 0.337 & 2648 & 21.82 & 0.338 & 2648 & 21.16 & 0.338 \\
\hline & \pm 18 & \pm 0.42 & \pm 0.001 & \pm 20 & \pm 0.48 & \pm 0.002 & \pm 15 & \pm 0.32 & \pm 0.001 \\
\hline \multirow[t]{2}{*}{10} & 2656 & 21.89 & 0.339 & 2609 & 22.26 & 0.335 & 2603 & 21.37 & 0.335 \\
\hline & \pm 22 & \pm 0.55 & \pm 0.002 & \pm 19 & \pm 0.46 & \pm 0.001 & \pm 19 & \pm 0.45 & \pm 0.002 \\
\hline \multirow[t]{2}{*}{15} & 2623 & 22.46 & 0.336 & 2625 & 21.94 & 0.336 & 2625 & 21.48 & 0.336 \\
\hline & \pm 18 & \pm 0.43 & \pm 0.001 & \pm 22 & \pm 0.54 & \pm 0.001 & \pm 17 & \pm 0.37 & \pm 0.001 \\
\hline \multirow[t]{2}{*}{30} & 2636 & 22.19 & 0.337 & 2619 & 21.70 & 0.336 & 2610 & 21.41 & 0.335 \\
\hline & \pm 19 & \pm 0.47 & \pm 0.001 & \pm 22 & \pm 0.55 & \pm 0.002 & \pm 17 & \pm 0.37 & \pm 0.001 \\
\hline \multirow[t]{2}{*}{60} & 2607 & 22.50 & 0.335 & 2616 & 21.85 & 0.336 & 2598 & 21.50 & 0.334 \\
\hline & \pm 15 & \pm 0.35 & \pm 0.001 & \pm 20 & \pm 0.47 & \pm 0.001 & \pm 21 & \pm 0.49 & \pm 0.002 \\
\hline \multirow[t]{2}{*}{120} & 2615 & 22.13 & 0.336 & 2631 & 21.84 & 0.337 & 2571 & 22.06 & 0.332 \\
\hline & \pm 18 & \pm 0.44 & \pm 0.001 & \pm 27 & \pm 0.70 & \pm 0.002 & \pm 19 & \pm 0.48 & \pm 0.002 \\
\hline \multirow[t]{2}{*}{180} & 2601 & 22.22 & 0.335 & 2660 & 20.66 & 0.339 & 2622 & 22.17 & 0.336 \\
\hline & \pm 17 & \pm 0.39 & \pm 0.001 & \pm 46 & \pm 1.30 & \pm 0.003 & \pm 17 & \pm 0.37 & \pm 0.001 \\
\hline \multirow[t]{2}{*}{240} & 2633 & 22.45 & 0.337 & 2629 & 21.46 & 0.337 & 2545 & 20.39 & 0.330 \\
\hline & \pm 18 & \pm 0.43 & \pm 0.001 & \pm 20 & \pm 0.47 & \pm 0.001 & \pm 19 & \pm 0.41 & \pm 0.002 \\
\hline \multirow[t]{2}{*}{300} & 2626 & 22.00 & 0.336 & 2611 & 21.40 & 0.335 & 2541 & 18.72 & 0.330 \\
\hline & \pm 20 & \pm 0.48 & \pm 0.002 & \pm 25 & \pm 0.63 & \pm 0.002 & \pm 21 & \pm 0.42 & \pm 0.002 \\
\hline
\end{tabular}


Typical values of the shorter lifetimes and their intensities, for the as-produced samples, were as follows: $\tau_{1}=(180 \pm 25) \mathrm{ps}, I_{1}=(20 \pm 10) \%, \tau_{2}=(375 \pm 25) \mathrm{ps}$, $I_{2}=(45 \pm 15) \%, \tau_{3}=(1050 \pm 150) \mathrm{ps}, I_{3}=(7.5 \pm 1.5) \%$. Within these error bars are included all fitted values of the measurements parameters obtained for ten different annealing times and for three different annealing temperatures. The parameters of the annealing process (its temperature and time) were quite different but the $R$ and $I_{4}$ values do not change remarkably, except for the samples annealed at $473 \mathrm{~K}$

Equation (1) has allowed us to combine the mean radius of the spherical well with the concept of the specific or fractional free volume in polymers. This fractional free volume, denoted by $f$, is defined as

$$
f=\left(V-V_{0}\right) / V=V_{\mathrm{f}} / V,
$$

where $V$ is the total macroscopic volume of the polymer, $V_{0}$ is the volume occupied by molecules, $V_{\mathrm{f}}$ is the free volume of the polymer. The fractional free volume might
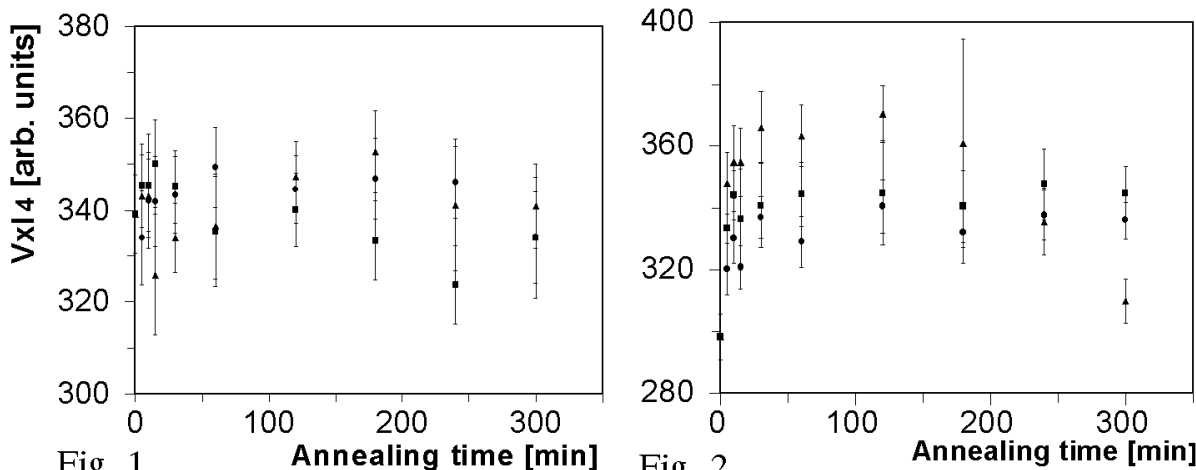

Fig. 1

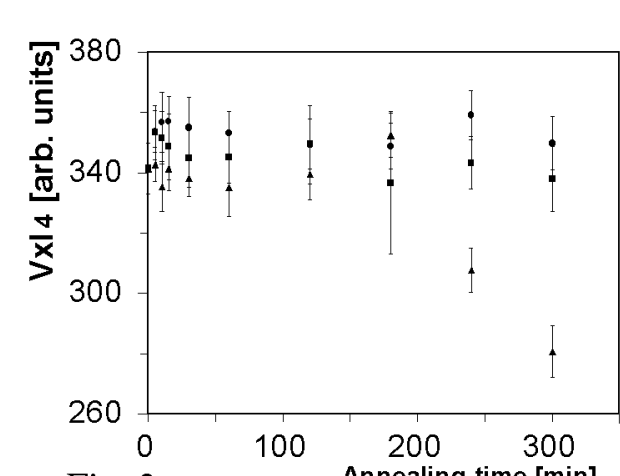

Fig. 3

Fig. 1. The $\left(V \times I_{4}\right)$ values for the as-produced samples vs. the annealing time at different temperatures $(\bullet-373 \mathrm{~K}, \mathbf{-}-423 \mathrm{~K}$ and full triangle $-473 \mathrm{~K})$.

Fig. 2. The $\left(V \times I_{4}\right)$ values for the irradiated samples vs. the annealing time at different temperatures $(\bullet-373 \mathrm{~K}, \mathbf{-}-423 \mathrm{~K}$ and full triangle $-473 \mathrm{~K})$.

Fig. 3 The $\left(V \times I_{4}\right)$ values for the orientated samples vs. the annealing time at different temperatures $(\bullet-373 \mathrm{~K}$, - $-423 \mathrm{~K}$ and full triangle $-473 \mathrm{~K}$ ). 
be determined from the lifetime measurements. The relative intensity of the $o$-Ps lifetime component, $I_{4}$, is assumed to be proportional to the number of the free volume holes because it gives the information on the o-Ps formation probability. Wang et al. [12] and Kobayashi et al. [13] proposed a semiempirical relation which may be used to evaluate the fractional free volume $f$

$$
f=A \times I_{4} \times V_{\mathrm{sph}},
$$

where $I_{4}$ is the relative intensity of the $o$-Ps lifetime component, $V_{\mathrm{sph}}=\left(4 \pi R^{3} / 3\right)$ $\left[\mathrm{nm}^{3}\right]$ is free volume of the single hole (the $R$ value is taken from Eq. (1)), $A$ is the normalisation constant. The $A$ value has not been measured in this work but as it is the constant, the $f$ value must be proportional to the product: $\left(I_{4} \times V_{\mathrm{sph}}\right)$. In Figs. 1, 2, and 3 the evaluations of this product are shown for three types of the measured samples. It is clear that for the as-produced samples there is no correlation between the $f$ values and both the annealing time and the annealing temperatures. Experimental points are randomly distributed about $f=337 \pm 15$. Similarly, for the irradiated samples there is no tendency between the $f$ values and the time and the temperature annealing at $373 \mathrm{~K}$ and $423 \mathrm{~K}$. However $f$ drops with the time annealing for the samples annealed at $473 \mathrm{~K}$ from about $f=355 \pm 10$ to about $f=310$. This decrease starts after $180 \mathrm{~min}$ of the time annealing. The same behaviour was observed for the orientated samples. The $f$ values for the samples annealed at $373 \mathrm{~K}$ and $427 \mathrm{~K}$ level off at about $f=350 \pm 15$. On the contrary, the experimental points for the samples annealed at $473 \mathrm{~K}$ show a tendency with the time. The $f$ drops from about 335 to about 280 for the annealing time longer than 180 min. Kobayashi et al. [13] and Madani et al. [14] observed a similar effect of the decreasing $f$ in poly(vinyl acetate) and in epoxy, respectively. As $\tau_{4}$ is proportional to the overlap of the positron and electron wave function in a free volume cavity it is obvious that $\tau_{4}$ will be correlated with the dimension of that cavity. The behaviour of the $f$ values for the as-produced samples suggests that the material of the samples was resistant to the changes of the temperatures and time annealing. Even for the highest (used in the investigation) temperatures and the longest time annealing, both values $R$ and $I_{4}$ were constant which resulted in levelling off the $f$ values. It indicates that neither the radii of the free volume nor the $o$-Ps formation probability were influenced by thermal treating. A similar effect was observed for the irradiated and orientated samples at $373 \mathrm{~K}$ and $423 \mathrm{~K}$. In spite of this, the decrease in the $f$ values was observed for these samples at the temperature annealing of $473 \mathrm{~K}$ for the time annealing longer than $180 \mathrm{~min}$ (Figs. 2 and 3 ). As $R$ values were almost constant for these samples it is the decrease in the relative intensity of the $o$-Ps lifetime component, $I_{4}$, that is responsible for the decrease in $f$. The decrease in the $f$ values might be explained taking into account the production process of the PE sheets. During this process polymer chains were strongly stretched, especially in the case of the orientated samples. Free volume spaces were created where o-Ps might live. When the samples were heated at $473 \mathrm{~K}$, for longer than $3 \mathrm{~h}$, the polymer chains shrank and some of the free volume disappeared. It might cause the decrease in $I_{4}$ and consequently the similar decrease in $f$. Unfortunately, the time annealing was no longer than $5 \mathrm{~h}$, in the work. It seems that the longer thermal treatment of the samples may explain this behaviour. 


\section{Conclusions}

Three different kinds of the thermo-shrunken PE were investigated by positron annihilation. Thermal treating of the as-produced samples does not seem to disturb the chains structure of the PE because the $f$ values are constant. The irradiated and orientated samples show the decrease in the $f$ values for high $(473 \mathrm{~K}$ ) temperature and long (longer than $3 \mathrm{~h}$ ) time annealing. It is supposed that this decrease is caused by the decrease in the relative intensity of the $o$-Ps lifetime component, $I_{4}$.

\section{References}

[1] Y.C. Jean, Microchemical J. 42, 72 (1990).

[2] O.E. Mogensen, in: Positron Annihilation in Chemistry, Ed. V.I. Goldanskii, in Springer series in Chemical Physics, Vol. 58, Springer-Verlag, Berlin 1995, p. 1.

[3] V. Flaris, M.D. Zipper, G.P. Simon, A.J. Hill, Polymer Eng. Sci. 35, 28 (1995).

[4] T. Suzuki, T. Miura, Y. Oki, M. Numajiri, K. Kondo, Y. Ito, Radiat. Phys. Chem. 45, 657 (1995).

[5] R.S. Brusa, M. Duarte Naia, D. Margoni, A. Zecca, Appl. Phys. A 60, 447 (1995).

[6] S. Shen, J. Lou, J. Cheng, K. Hong, Q. Zhu, X. Zhou, Phys. Status. Solidi. A 147, 447 (1995).

[7] S.J. Wang, C.L. Wang, B. Wang, J. Radioanal. Nucl. Chem., Articles 210, 407 (1996).

[8] W. Osoba, Acta Phys. Pol. A 95, 632 (1999).

[9] P. Kirkegaard, N.J. Pedersen, M. Eldrup, PATFIT-88, Ris $\varnothing-M-2740$, Ris $\varnothing$ National Laboratory, Roskilde (Denmark) 1989.

[10] S.J. Tao, J. Chem. Phys. 56, 5499 (1972).

[11] M. Eldrup, D. Lightbody, J.N. Sherwood, Chem. Phys. 63, 51 (1981).

[12] Y.Y. Wang, H. Nakanishi, Y.C. Jean, T. Sandreczki, J. Polym. Sci. Part B, Polymer Phys. 28, 1431 (1990).

[13] Y. Kobayashi, W. Zheng, E.F. Meyer, J.D. McGervey, A.M. Jamieson, R. Simha, Macromol. 22, 2302 (1989).

[14] M.M. Madani, R.R. Miron, R.D. Granata, J. Coatings Technology 69, 45 (1997). 